\title{
Kanban: A Definite Answer for Effective Project Execution in Uncertainties
}

\author{
Kamini Godbole ${ }^{1}$, Dr. Jitesh Neve ${ }^{2}$ \\ Sr. Project Manager, Persistent Systems Ltd, Pune, India ${ }^{1}$ \\ Module Lead, Persistent Systems Ltd., Pune, India ${ }^{2}$
}

\begin{abstract}
As a process setting practitioner I have come across many a times that either customer is not really understanding what they want or a vendor unable to articulate and provide solution which meets $90-95 \%$ of customer requirements. There are various factors that actually make this happen at both ends such as novice customer / vendor, emerging technologies, vendor unable to visualize customer vision, business, skilled resources not available, fast changing end user needs, no more valid requirements etc. Root cause of many of these reasons is agility which is growing due to fast pace and ever developing technology and changing needs. In any industry without a proper plan it is not easy to keep delivering solution of any type to meet with ever changing demands of customer. Kanban method is helping in such unpredictable delivery.
\end{abstract}

Keywords: TDD (Test Driven Development), BDD (Behaviour Driven Development), XP (Extreme programming), WIP (Work in Progress)

\section{INTRODUCTION}

Enterprise agility is experienced more predominantly irrespective of the business domain. The tools / people/ processes which would help cater agility are being looked forward by industries. The "wait period" is tried to minimize to possible extent for market shares to grab hence it's the buzz of this era. It focuses on shifting mind-set of organizational workforce into agile by fostering changes via learning inducing innovations to accelerate.

Agile as per its manifesto gives importance to achieve maximum customer satisfaction through continuous customer engagements, give value add delivery at regular intervals, time box all the activities. There are various methodologies in which this all can be achieved such as scrum, TDD (Test Driven Development), BDD (Behaviour Driven Development), XP (Extreme programming). One way is Kanban.

The reason why agile approach gain popularity in short time than conventional waterfall model was -

$>$ Each phases are sequential needs completion to start on new phase.

$>$ In case incorrect requirements are freezed this would lead to incorrect solution delivery.

$>$ Changes become too expensive to accommodate.

$>$ Defects detected in later phase of lifecycle while fixing causes effect on the previous phases.

$>$ Delays completion of a phase have cascading effect on successive phases leading to schedule and effort impacts.

$>$ Incorrect deliveries not meeting expectations lead to customer dissatisfaction and becomes too difficult to make changes into every impacted area.

\section{LITERATURE SURVEY}

Agile has following main ingredients to get it working irrespective of which methodology is used to apply it.

- Deliverables - Minimum Viable Product, Product Backlog Items, Sprint Backlog Items, Impediment List

- Roles- Product Owner, Scrum Master, Development Team, Stake holders which could be customer and/ or their end user.

- Ceremonies - Daily Stand up meeting, Product back log grooming, Sprint planning, Sprint retrospective. 
International Journal of Advanced Research in Computer and Communication Engineering ISO 3297:2007 Certified

Vol. 6, Issue 6, June 2017

Normal Scrum model which is widely practiced as depicted in fig 2 .

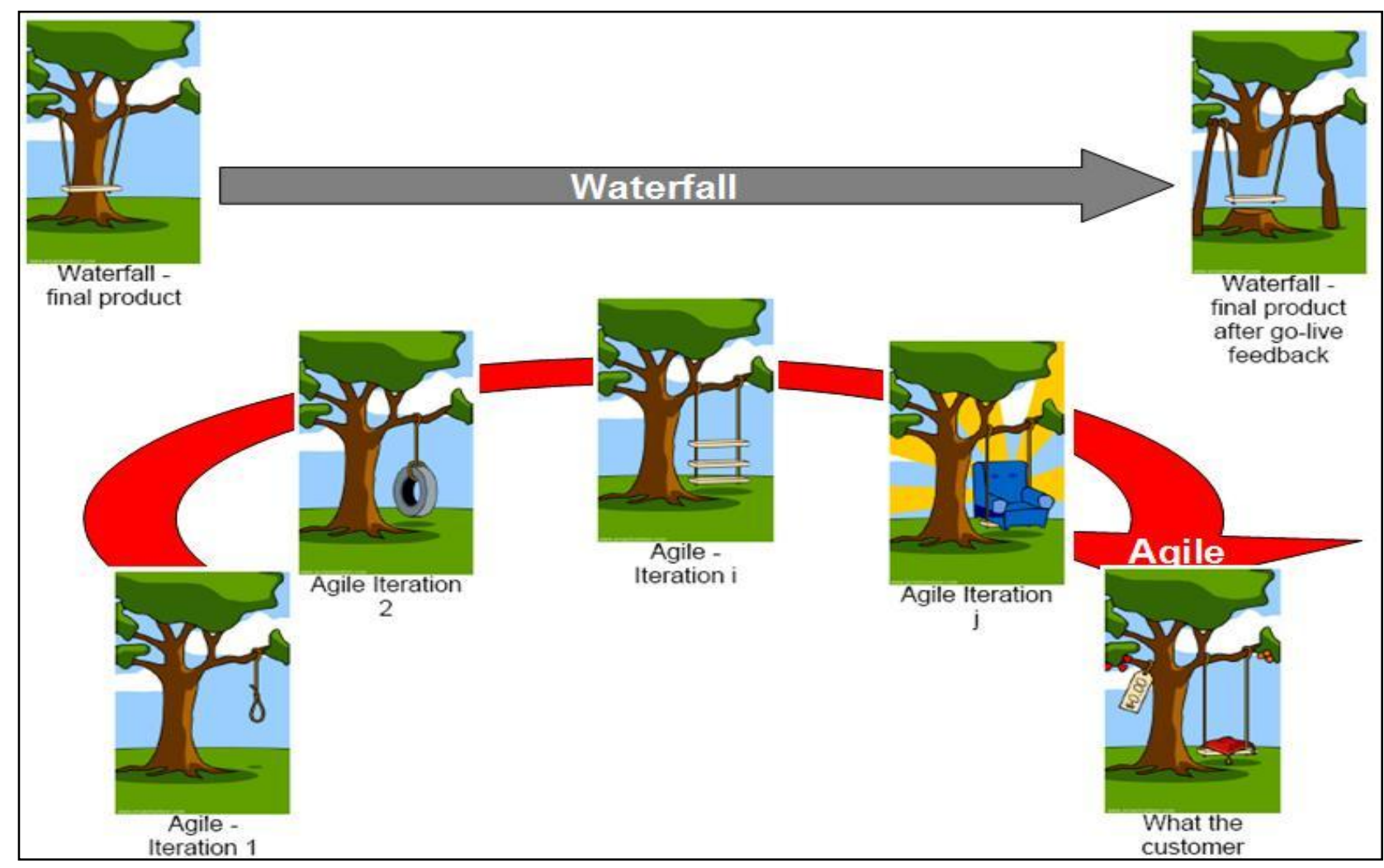

Fig. 1. Example of an unacceptable low-resolution image

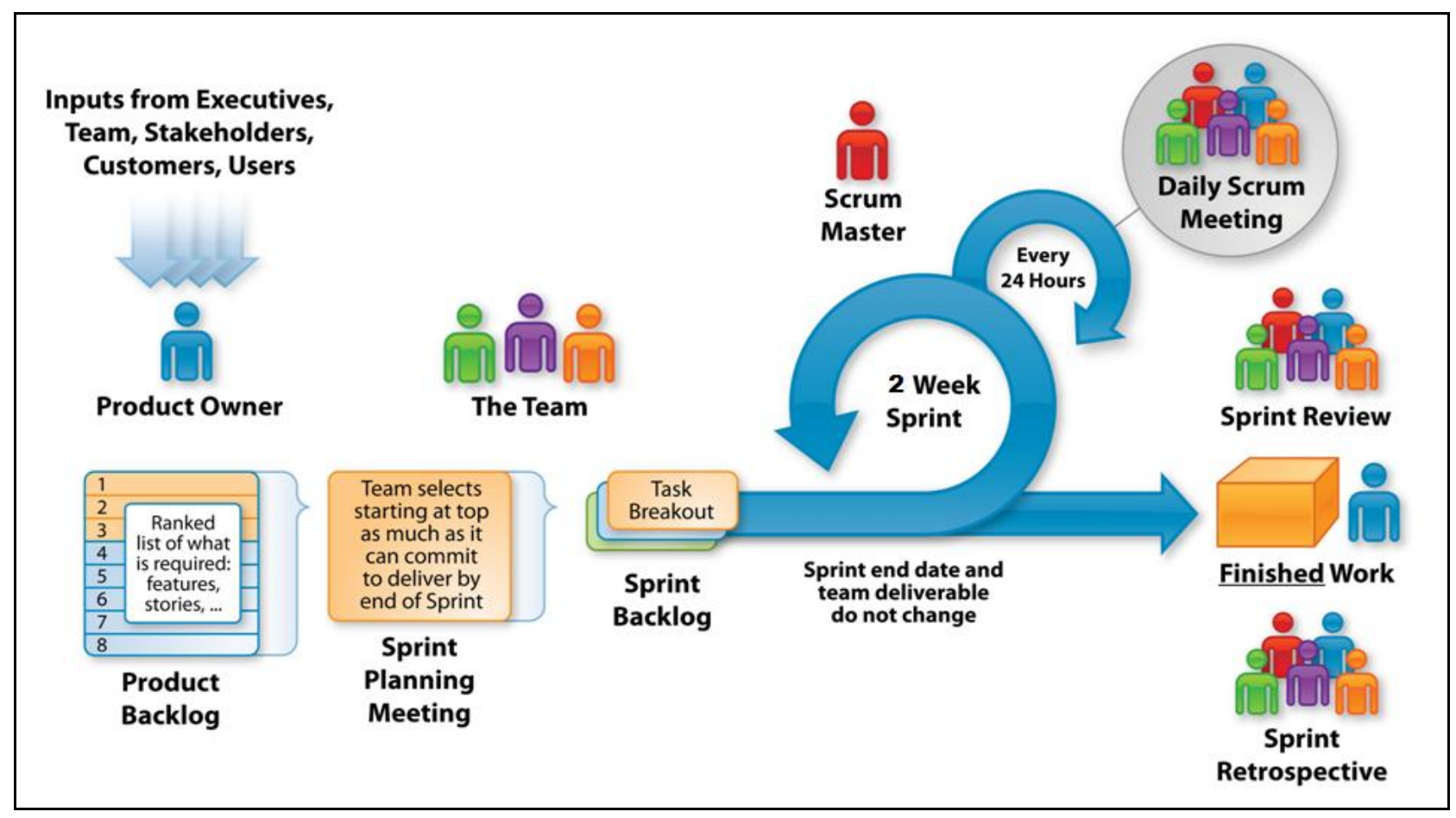

Fig. 2. Scrum Model of agile 
Enterprise agility basically means an ability or flexibility to adopt and give adequate responses to changes in the ecosystem its breathing in. This can be practiced by inducing

1. Results agility

2. Self-awareness

3. Change agility

4. People agility

5. Mental agility

The degree to achieve success all depends on all people's contribution and collaboration.

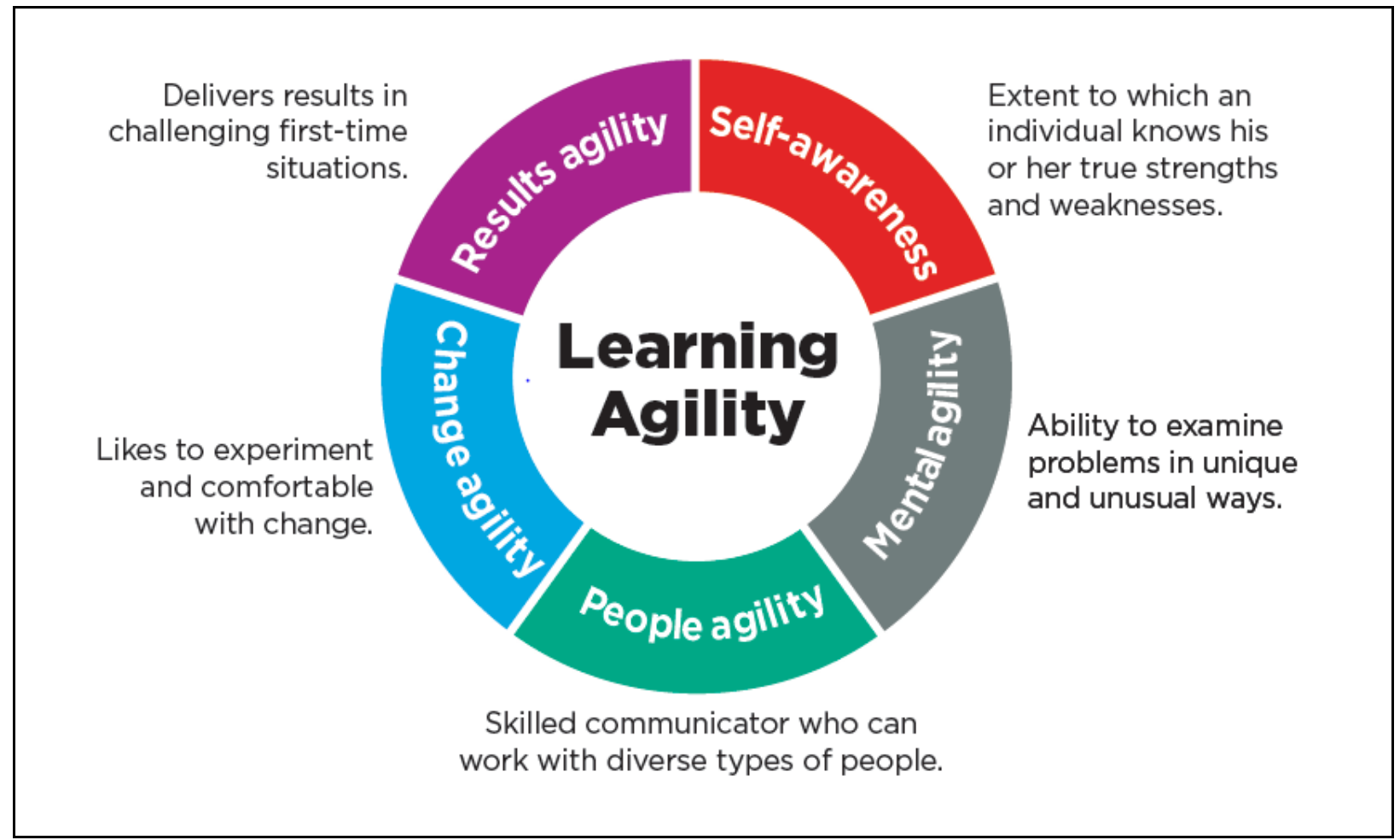

Fig. 3. Agility mindset success factors

The agility leads to rapid requirement changes based on business needs which can call for lot of rearrangements of plans which are WIP (Work in Progress) this can create a lot of confusion, chaos amongst stakeholders. Many questions need to get addressed such as what to be targeted, when to be delivered, what should be accepted at the current point of time.

\section{KANBAN: VISUALIZE YOUR FLOW}

Enterprise agility is practiced where organizations believe in stepping up and provide rapid strategic responsiveness to their end users. This would involve people willing learning agility, understanding, planning business goals for targeted period and tapping industry wide mega micro trends. Most of the times information flowing in the form of document from one end to other might not make much impact and as rightly said "A picture speaks million words" Kanban boards makes that significance.

It gives comprehensive view, feeling in control of how projects are performing at a given point of time. Kanban is found out to be working pretty well with organization who need lean method or do not want to put in much efforts on project tracking to meet their customer needs or people who do not have much exposure on these methodologies. These boards can be produced and tracked in wide variety of ways by making use of tools as per engagement needs. Typical Kanban boards are seen as depicted in fig. 4. 


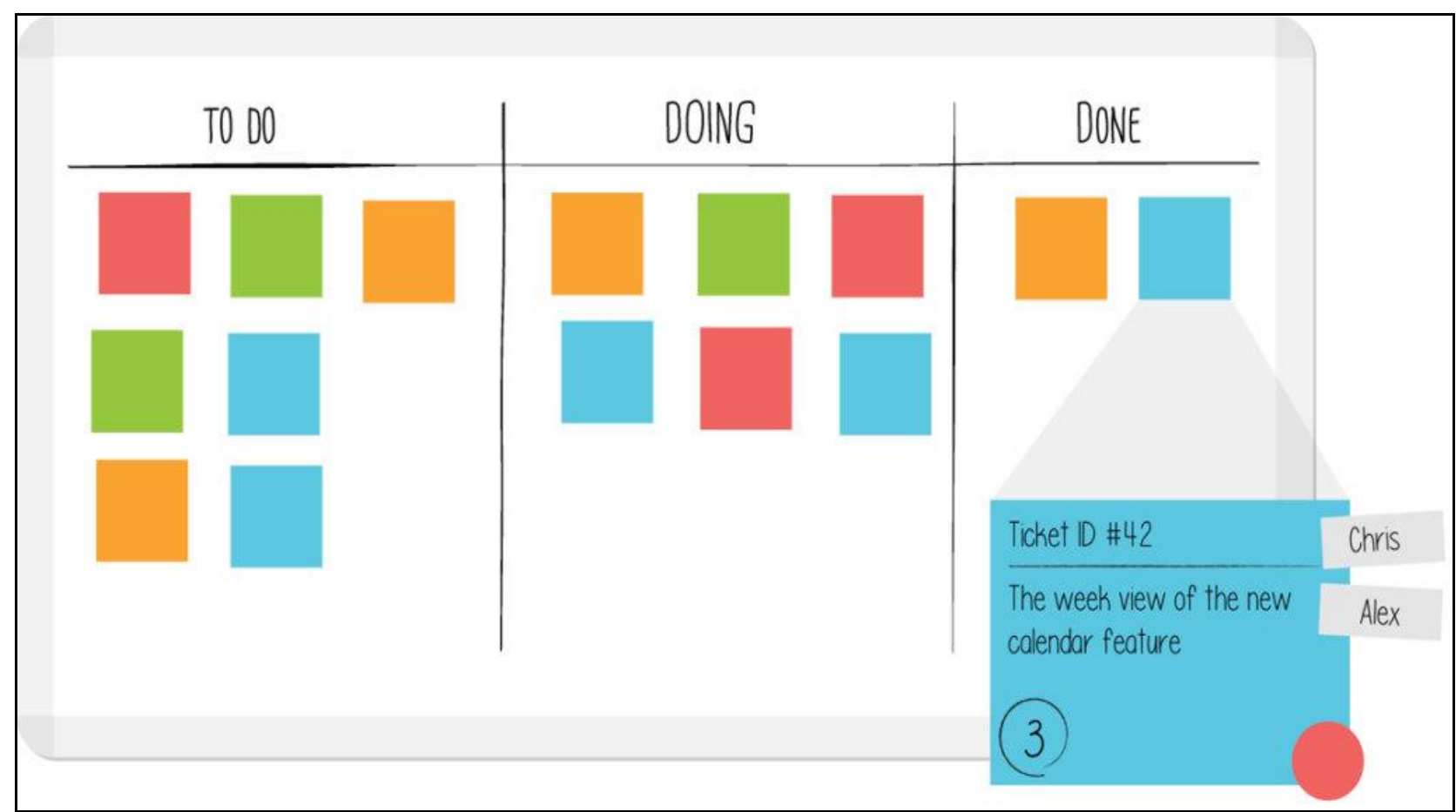

Fig. 4. Kanban board one of the way to track

\section{CUSTOMER EXPERIENCE}

An example, where customer organization 'ABC Ltd.' though had potential to invest in world class solution but was not exposed to how process can be used as aid to achieve business objectives set faster, smoother in effective way. Vendor was offered to have a platform developed and some enhancements to already existing platforms. The conflicts began when customer was unable -

- to priorities requirements on a platform

- $\quad$ to priorities on which platform to go live with changes

- $\quad$ to fix requirements for an iteration, gave changes at a random during the work in progress or about to finish

- $\quad$ to understand agile method working

- $\quad$ to understand not all people would be working all the time on all platforms in parallel

- $\quad$ To know making changes can cause waste of efforts.

This lead to dissatisfied customer not having complete product with all desired requirements. Vendor too was over burned with unhappy team members. Customer believed that vendor is not utilizing the entire workforce but frequent changes imposed resulted in product quality doubtable and timelines slippages.

Solution to all this came up was Kanban where the trust, transparency emerged to have streamlined approach. We used the approach as the following way -

Precondition -

$\checkmark \quad$ Basic hygiene practices were put in place at customer end.

$\checkmark \quad$ Change management, Kanban board overview was introduced.

$\checkmark \quad$ Capacity planning was done.

$\checkmark \quad$ Entry, Exit criteria for requirements got defined

Thus,

$\checkmark \quad$ Kanban boards were established to showcase project as is state on time stamp state

$\checkmark \quad$ Threshold for work in progress was put up based on the capacity available.

$\checkmark \quad$ Discipline and cadence got set at both customer and vendor end to formalize the process.

The changes which used to be reported multiple times during work in progress eventually started reducing, all stakeholders could track projects, team members were satisfied and better deliveries started emerging. 


\section{Conclusion}

We are living in the world where faster time to market, meeting customer requirement faster better to provide value added delivery is becoming the bear minimum ask. This can't be avoided or reduced. Kanban as any other methodology would offer frequent deliverables, quicker decision, easy to change direction, better for ROI, customer engagement achieved more, and wasteful non-productive meetings are reduced. But more to it Kanban improves information visibility that assures great work environment there by achieving customer satisfaction. Although enterprise agility does not encourage do away with prioritization, planning and release plans.

Thus Kanban can work well given a situation where there is good roadmap already available as well as there is not much clarity and control on the work packet frequencies. This can be clubbed with scrums and made scrum ban too. Say yes to enterprise agility with Kanban.

\section{ACKNOWLEDGMENT}

I thank the project teams for giving me the freedom to implement the solution. Going through the process from adhoc to process oriented was real change process both with client and we vendor team. I would like to thank Dr. Jitesh Neve for encouraging me to come up with write up on this case which would become one of the example of Kanban implementation.

\section{REFERENCES}

[1] N. Singh, Kwok Hung Shek, Dave Meloche, "The Development of a Kanban System: A Case Study", International Journal of Operations \& Production Management, ISSN: 0144-3577, Vol. 10, Issue: 7, pp.28-36, available online at: https://doi.org/10.1108/01443579010140498.

[2] Ahmad Naufal Bin Adnan, Ahmed Bin Jaffar, Noriah Binti Yusoff and Nurul Hayati Binti Abdul Halim, "Implementation of Just in Time Production through Kanban System", Industrial Engineering Letters, ISSN:2224-6096 (Paper), ISSN: 2225-0581 (online) Vol.3, No.6,Page: 1121, year-2013.

[3] M. Apreutesei, I.R. Arvinte, E. Suciu, D. Munteanu, "Application of Kanban System for Managing Inventory", Bulletin of the Transilvania University of Braşov, Vol-3, No-52, Series1-Engg. Sciences, pages: 161-166, year 2010.

[4] Ritesh Kumar Shrivastava, and Dr. Sridhar K., "Productivity \& Quality Improvement Through Kanban - A Case Study", International Journal of Advanced Engineering Research and Studies, E-ISSN:2249-8974, Presented at: "BITCON-2015 Innovations for National Development" National Conference on: Innovations in Mechanical Engineering for Sustainable Development, Vol-4 (2), page: 251-255, Mar-2015.

[5] C. Sendil Kumar and R. Panneerselvam, "Literature review of JIT-KANBAN system", International Journal of Advanced Manufacturing Technologies, Vol-32, Page-393-408, year: 2007, DIO:10.1007/s00170-005-0340-2, available online at https://link.springer.com/article/10.1007/s00170-005-0340-2.

[6] M.Raju Naik , E.Vijaya Kumar and B.Upender Goud, "Electonic Kanban System", International Journal of Scientific and Research Publications, Volume 3, Issue 3, March 2013, ISSN 2250-3153, page:1-6.

\section{BIOGRAPHIES}

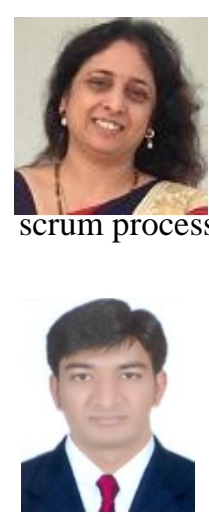

Kamini Godbole, I have rich experience on delivering projects for more than a decade and now having turned into process practitioner suggest alternatives / solutions for project execution problems via setting up processes. I am B.C.S., M.C.M. and have been certified on ISTQB, Prince-2, CSM and ITIL foundation course. I love reading books, blogs and have been blogging as time permits on agile leadership in my current organizations portal. I do conduct trainings on risk management, metrics, agile leadershi

Dr. Jitesh Neve, I am a post Ph.D. research scholar. I am awarded with 'Honorary Doctorate' from 'University of Swahili, Republic of Panama' towards the outstanding contribution in the field of research in Computer Science and Engineering. I am also awarded with 'Youngest Doctorate Award' from the same university. I have around 4 years of experience in IT industry. I did my technical graduation in IT from Pune University in 2013. 